\title{
The study of the genetic diversity of oat varieties cultivated in the Tyumen region, by avenin-coding loci
}

\author{
Lyubimova A.V. ${ }^{1,2 *}$, Eremin D.I. ${ }^{1}$ \\ ${ }^{1}$ Northern Trans-Ural State Agricultural University, Tyumen, Russia \\ ${ }^{2}$ Scientific Research Institution of Agriculture for Nothern Trans-Ural Region-Branch of Tyumen \\ Scientific Centre, SB RAS, Tyumen, Russia \\ *e-mail: ostapenkoav88@yandex.ru
}

Oats - one of the main cultivated crops in the Tyumen region. Due to the active breeding work, currently in the region grow oats varieties only local selection. An important condition for increasing yields and crop resistance to adverse factors is the preservation of the high genetic diversity of the species. To evaluate this indicator, alleles of prolamincoding loci are very convenient. We analyzed the electrophoretic spectra of prolamins of 18 varieties of oats, included in the State Register of breeding achievements in the Tyumen region from the 1930 s to the present. The alleles of avenin-coding loci (ACL) $A v n A, A v n B, A v n C$ are identified. In total, 12 alleles were identified at the $A v n A$ locus, 10 at the $A v n B$ locus, and 8 at the $A v n C$ locus. Among the studied varieties, 11 were homogeneous in component composition of avenin. The remaining varieties had two biotypes. On the basis of data on the frequency of occurrence the alleles of ACL, the average gene diversity $(\mathrm{H})$ was calculated. In order to evaluate the genetic diversity of varieties in different periods of time, all the studied samples were combined into groups. One group included varieties cultivated in the same ten-year period. It was established that the minimum values of genetic diversity (0.33) were characteristic of varieties cultivated in 1930-1950. With the advent of new varieties, including domestic breeding, the $H$ value increased and reached its maximum (0.78) in 1970-1980. By 2000, this figure fell to 0.70 , which is associated with the processes of variety changing and substitution of foreign varieties with local breeding varieties. As a result, the frequency of occurrence the alleles of ACL characteristic of these varieties has changed. To date, the genetic diversity of oat varieties cultivated in the region is 0.75 . The high value of $\mathrm{H}$ of oats indicates a well-conducted breeding work with this crop in the Tyumen region. 